\title{
Improved Expression for Estimation of Leakage Inductance in E Core Transformer Using Energy Method
}

\author{
Sivananda Reddy Thondapu, ${ }^{1}$ Mangesh B. Borage, ${ }^{2}$ \\ Yashwant D. Wanmode, ${ }^{1}$ and Purushottam Shrivastava ${ }^{1}$ \\ ${ }^{1}$ Pulse High Power Microwave Section, Raja Ramanna Centre for Advanced Technology, Indore 452013, India \\ ${ }^{2}$ Power Supplies and Industrial Accelerator Division, Raja Ramanna Centre for Advanced Technology, Indore 452013, India
}

Correspondence should be addressed to Sivananda Reddy Thondapu, sivananda@rrcat.gov.in

Received 31 December 2011; Revised 13 April 2012; Accepted 29 April 2012

Academic Editor: Pavol Bauer

Copyright (c) 2012 Sivananda Reddy Thondapu et al. This is an open access article distributed under the Creative Commons Attribution License, which permits unrestricted use, distribution, and reproduction in any medium, provided the original work is properly cited.

\begin{abstract}
This paper proposes a simpler and more accurate expression for estimation of leakage inductance in $E$ core transformer, which is the most widely used transformer structure. The derived expression for leakage inductance accounts for the flux extending into air. The finite element method (FEM) analysis is made on the secondary shorted transformer to observe the $H$-field pattern. The results obtained from FEM analysis are used for approximating the field that is extending into air to derive an expression for leakage inductance. This expression is experimentally validated on prototype transformers of different core dimensions.
\end{abstract}

\section{Introduction}

Transformer is one of the basic building blocks of many power converters. The following are some of the cases where accurate estimation of leakage inductance is required.

(i) Different resonant converter topologies, discussed in [1-5], use parasitics of transformer as a part of resonant tank network. For designing power converter with such topologies, one requires accurate estimation of leakage inductance.

(ii) In hard switched converters, in every cycle the energy stored in the parasitics appears as loss in converter. In estimation of efficiency of such converters, one needs to estimate leakage inductance before hand.

(iii) For designing snubber circuits to limit device voltage during turn-off transients [6-8], one needs to estimate leakage inductance. These turn-off transients mainly occur due to energy stored in the leakage inductance of the transformer.

Methods that are usually employed for estimation of leakage inductance are (i) energy method [8-13] and (ii) method of mutual fluxes.
In energy method, the energy stored in magnetic field of the secondary shorted transformer is calculated and equated to $(1 / 2) L_{\text {leak }} I_{p}^{2}$ where $L_{\text {leak }}$ is the leakage inductance of the transformer when referred to primary, and $I_{p}$ is current flowing through primary.

The $H$-profile inside the coil is calculated using Ampere's law. The energy stored in magnetic field is calculated by evaluating the volume integral in (1):

$$
E_{\text {stored }}=\frac{\mu}{2} \iiint H^{2} d v=\frac{1}{2} L_{\text {leak }} I_{p}^{2}
$$

The expression derived for leakage inductance using energy method is independent of frequency. Hence, it does not consider any frequency-dependent effects on leakage inductance. The energy method is used for comparing leakage inductance, in different winding configurations.

On the other hand, method of mutual fluxes uses Maxwell's equations to predict the leakage inductance more accurately at high frequencies. As this method accounts for frequency-dependent effects like eddy current losses and altered flux pattern due to eddy currents, it gives more accurate results, particularly at high frequencies. In [14], a frequency-dependent formula is presented to find leakage inductance in a toroidal core transformers. 


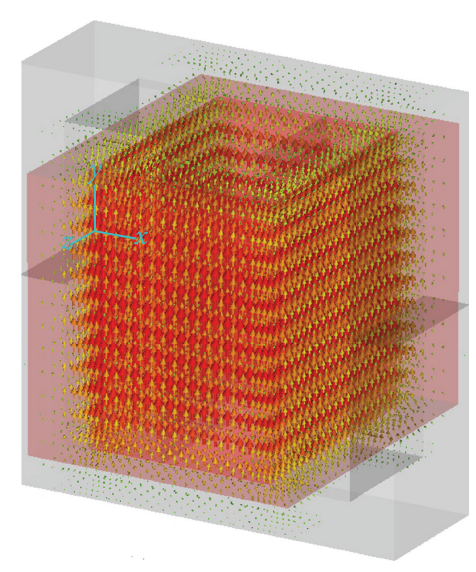

(a) Perspective

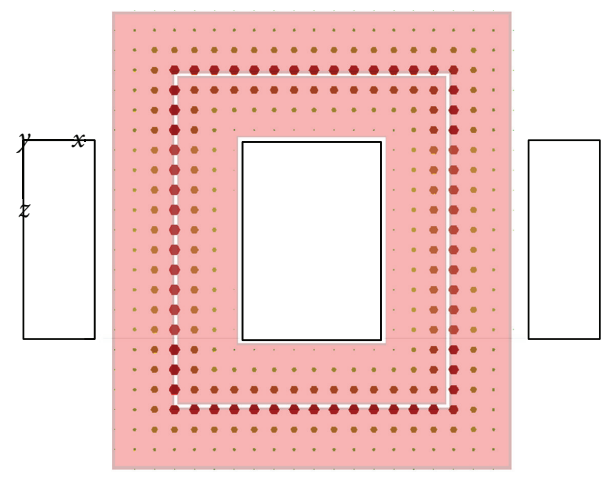

(c) Top view

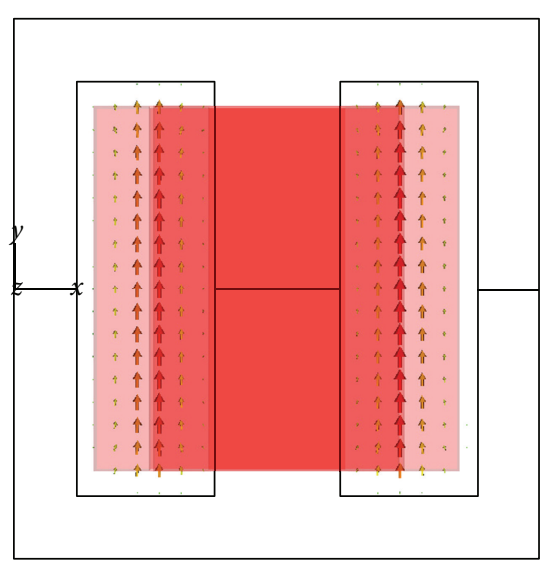

(b) Front view

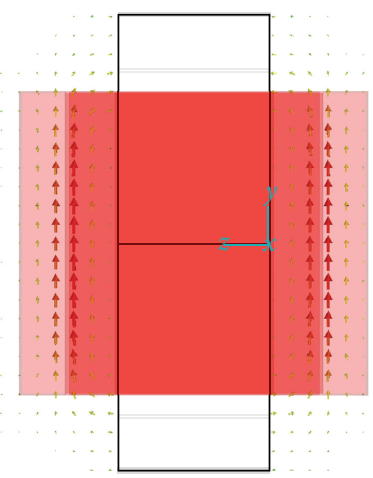

(d) Side view

FIgURE 1: Simulation result of FEM analysis.

In this paper, an expression for leakage inductance is derived using energy method. Expression derived accounts for the flux that extends into air in a secondary shorted transformer, which is not considered earlier $[8,10,11]$. Therefore, the estimated leakage inductance using this expression has better accuracy.

\section{Estimation of Leakage Inductance on E Core Transformer}

FEM analysis on secondary shorted transformer is made using CST Ver 2008.5 (with magneto-static solver). The simulation result of FEM analysis is shown in Figure 1. The simulation result is the $H$-field pattern of secondary shorted $E$ core transformer. This gives an idea of profile of $H$-field from the surface of the core to the outer surface of the whole winding. The profile of $H$-field of a $E$ core transformer and its winding configuration is shown in Figures 2 and 3, respectively.

Energy stored in the magnetic field in the secondary shorted transformer is equated to energy stored in leakage inductor, which is given in (1).

The volume represented with purple color in Figure 4 is considered for volume integration. This constitutes (i) the volume occupied by the coils and (ii) the volume formed by extrusion of the coils along the centre limb of the core, excluding the volume of the core. The flux extends into air shown in Figure 5. The volume shown in Figure 4 is divided into four parts, whose top view is shown in Figure 3. The profile of $H$-field is calculated using Ampere's law, the same profile is observed in FEM analysis. The $H$-profile is expressed mathematically in (2):

$$
H(z)= \begin{cases}H_{m} \frac{z}{h_{1}} & 0<z<h_{1}, \\ H_{m} & h_{1}<z<h_{1}+t, \\ H_{m}\left(\frac{h_{1}+h_{2}+t-z}{h_{2}}\right) & h_{1}+t<z<h_{1}+h_{2}+t .\end{cases}
$$

Using $H$-profile given in (2) to evaluate volume integral given in (1), we get expression of the leakage inductance:

$$
L_{\text {leak }}=\frac{1}{3} \frac{\mu_{0} N_{1}^{2}}{F^{2}}(h+2 t)[F C+B(E+2 h)]
$$

where $h=h_{1}+h_{2}+t$ is total thickness of the winding measured from the surface of the core to the outer surface of the outer winding, $t$ is total thickness of the insulation used between the layers. $B, C, E, F$ is are the dimensions of the $E$ core shown in Figure 6. 

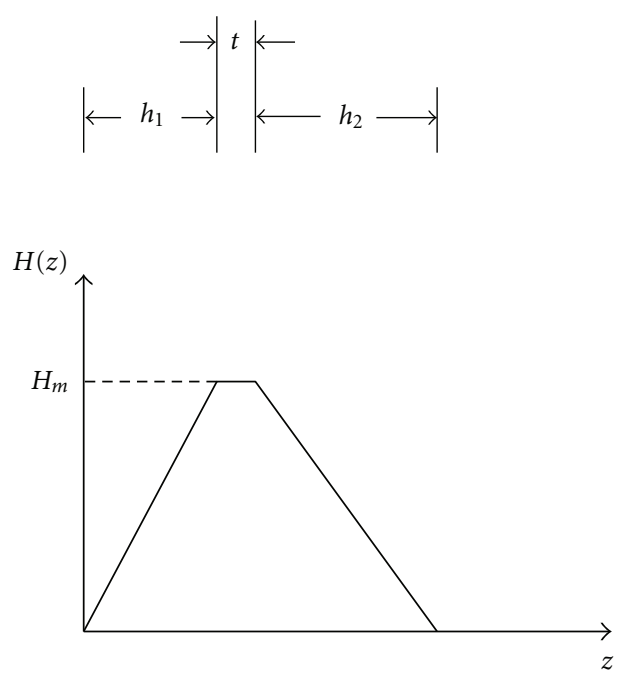

Figure 2: Profile of $H(z)$ from the surface of the core.

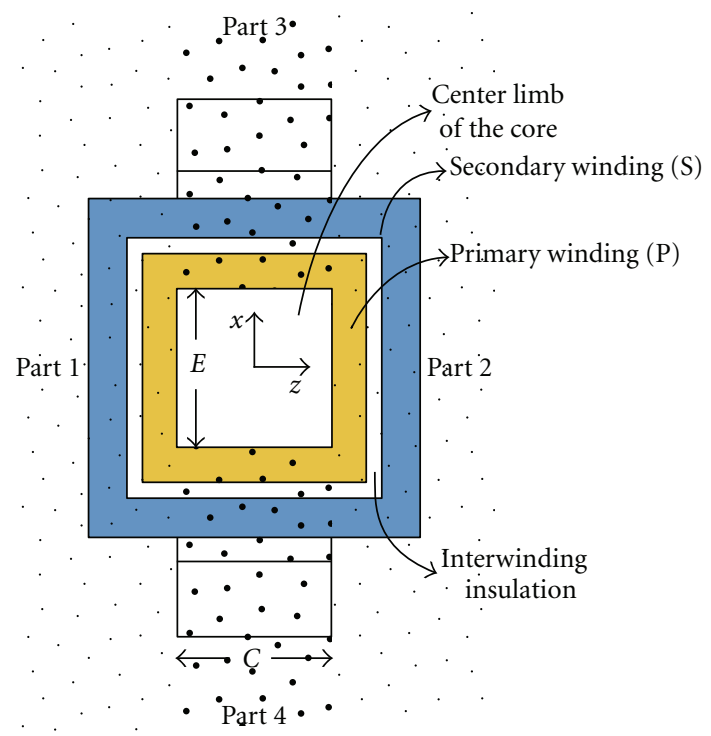

Figure 3: Top view of $E$ core transformer with windings.

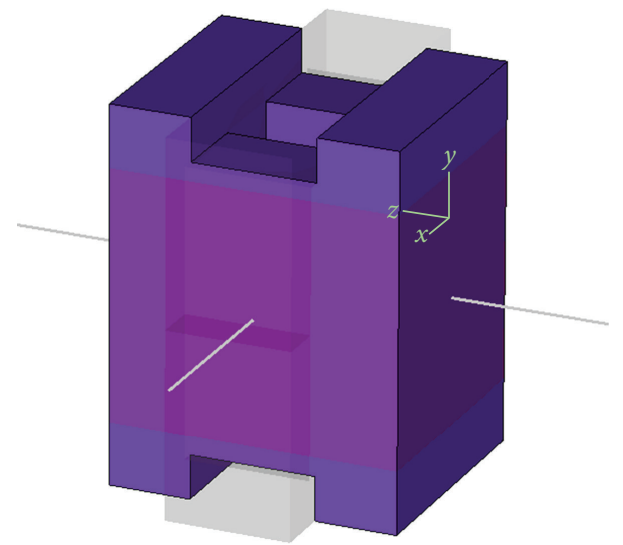

FIgURE 4: Volume around the core considered for integration.

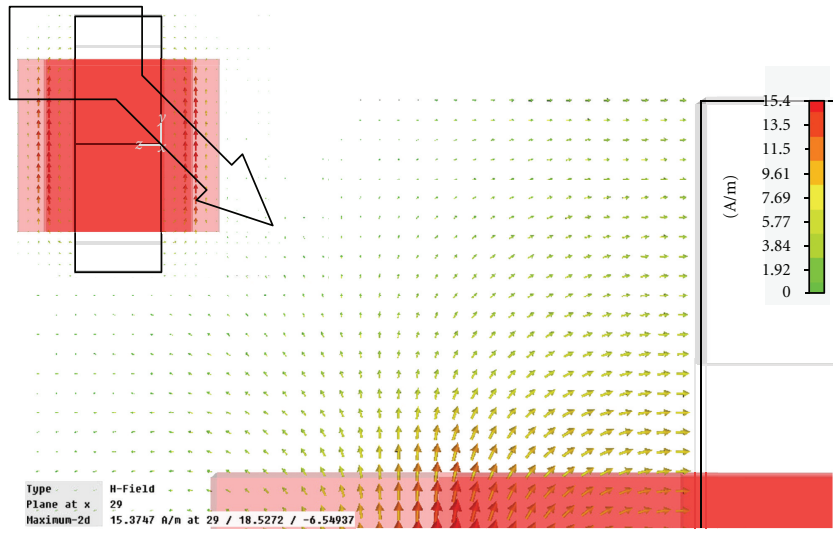

FIgURE 5: Scaled side view to show the flux that extends into air. 
TABLE 1: EE core transformer with interwinding insulation.

\begin{tabular}{|c|c|c|c|}
\hline Sample no. & 1 & 2 & \\
\hline Core type & $\mathrm{EE} 42 / 21 / 15$ & EE65/38/13 & \\
\hline$F$ & $14.45 \mathrm{~mm}$ & $22.65 \mathrm{~mm}$ & \\
\hline C & $15.20 \mathrm{~mm}$ & $13.45 \mathrm{~mm}$ & \\
\hline$B$ & $21.10 \mathrm{~mm}$ & $32.59 \mathrm{~mm}$ & \\
\hline$E$ & $12.05 \mathrm{~mm}$ & $19.77 \mathrm{~mm}$ & \\
\hline$h_{1}$ thickness of primary & $3.20 \mathrm{~mm}$ & $3.81 \mathrm{~mm}$ & \\
\hline$h_{2}$ thickness of secondary & $1.90 \mathrm{~mm}$ & $1.55 \mathrm{~mm}$ & \\
\hline$t$ thickness of insulation & $1.27 \mathrm{~mm}$ & $2.00 \mathrm{~mm}$ & \\
\hline$N_{1}$ & 34 & 48 & \\
\hline $\mathrm{N}_{2}$ & 17 & 24 & \multirow[b]{2}{*}{$\begin{array}{l}\text { Winding } \\
\text { configuration }\end{array}$} \\
\hline \multirow[b]{2}{*}{ Photograph } & & & \\
\hline & & & \\
\hline Leakage inductance $L_{\text {leak,earlier }}$ from (5) & $11.91 \mu \mathrm{H}$ & $22.52 \mu \mathrm{H}$ & \\
\hline Leakage inductance $L_{\text {leak }}$ from (3) & $15.32 \mu \mathrm{H}$ & $28.21 \mu \mathrm{H}$ & \\
\hline Leakage inductance $L_{\exp }$ at $10 \mathrm{kHz}$ measured & $14.13 \mu \mathrm{H}$ & $26.76 \mu \mathrm{H}$ & \\
\hline$\%$ deviation of $L_{\text {exp }}$ from calculated $L_{\text {leak,earlier }}$ & $15.71 \%$ & $15.84 \%$ & \\
\hline$\%$ deviation of $L_{\exp }$ from calculated $L_{\text {leak }}$ & $8.38 \%$ & $5.12 \%$ & \\
\hline
\end{tabular}

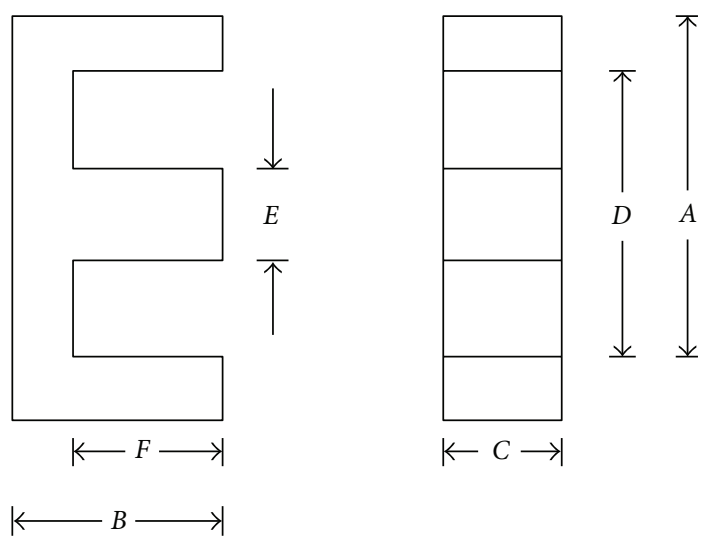

Figure 6: $E$ core dimensions given in data sheets.

It is seen in $[8,11-13]$, by sandwiching the windings, leakage inductance reduces by $p^{2}$ times, where $p$ is the number of interfaces between primary and secondary [8]:

$$
L_{\text {leak }}=\frac{1}{3 p^{2}} \frac{\mu_{o} N_{1}^{2}}{F^{2}}(h+2 t)[F C+B(E+2 h)] .
$$

\section{Experimental Results}

Three different samples are made to validate the derived expression. The results are compared with the expressions available in literature. The expression given in $[8,10,11]$ is replaced with the dimensions of the core (shown in Figure 6) and the dimensions of windings will give (5):

$$
L_{\text {leak,earlier }}=\frac{1}{3 p^{2}} \frac{\mu_{o} N_{1}^{2}}{F^{2}}(h+2 t) F(C+E+2 h) .
$$

Sample no. 1 is made with $E$ core (EE42/21/15) wound with stranded conductor made with three conductors of 24 SWG. With interwinding insulation of thickness $1.27 \mathrm{~mm}$ is used. Standard winding configuration as shown in Table 1 is used to wind primary and secondary.

Sample no. 2 is made with $E$ core (EE65/38/13) wound with stranded conductor made with three conductors of 24 SWG. With interwinding insulation of thickness $2.00 \mathrm{~mm}$. Standard winding configuration as shown in Table 1 is used to wind primary and secondary.

Sample no. 3 is made with $E$ core (EE42/21/15) wound with stranded conductor made with two conductors of 24 SWG. With total interwinding insulation of thickness $0.46 \mathrm{~mm}+0.26 \mathrm{~mm}=0.72 \mathrm{~mm}$ is used. Sandwiched winding 
TABLE 2: EE core transformer with sandwiched winding (P/2, S, P/2).

\begin{tabular}{|c|c|c|}
\hline Sample no. & 3 & \\
\hline Core type & $\mathrm{EE} 42 / 21 / 15$ & \\
\hline$F$ & $14.45 \mathrm{~mm}$ & \\
\hline C & $15.20 \mathrm{~mm}$ & \\
\hline$B$ & $21.10 \mathrm{~mm}$ & \\
\hline$E$ & $12.05 \mathrm{~mm}$ & \\
\hline$h_{1}$ thickness of primary half & $1.41 \mathrm{~mm}$ & \\
\hline$h_{2}$ thickness of secondary & $2.93 \mathrm{~mm}$ & \\
\hline$h_{3}$ thickness of primary half & $1.52 \mathrm{~mm}$ & \\
\hline$t_{1}$ thickness of insulation & $0.46 \mathrm{~mm}$ & \\
\hline$t_{2}$ thickness of insulation & $0.26 \mathrm{~mm}$ & \\
\hline$N_{1}$ & 46 & \\
\hline $\mathrm{N}_{2}$ & 44 & \multirow[b]{2}{*}{$\begin{array}{l}\text { Winding } \\
\text { configuration }\end{array}$} \\
\hline \multirow[b]{2}{*}{ Photograph } & & \\
\hline & & $\mathrm{P} / 2$ \\
\hline Leakage inductance $L_{\text {leak,earlier }}$ from (5) & $4.94 \mu H$ & \\
\hline Leakage inductance $L_{\text {leak }}$ from (4) & $6.37 \mu H$ & \\
\hline Leakage inductance $L_{\text {exp }}$ at $10 \mathrm{kHz}$ measured & $5.91 \mu H$ & \\
\hline$\%$ deviation of $L_{\exp }$ from calculated $L_{\text {leak,earlier }}$ & $16.41 \%$ & \\
\hline$\%$ deviation of $L_{\exp }$ from calculated $L_{\text {leak }}$ & $7.82 \%$ & \\
\hline
\end{tabular}

configuration as shown in Table 2 is used to wind primary and secondary.

All the measurements for leakage inductance are made by shorting the secondary. The measurements are made with LCR meter (make: Gw instek Model: LCR-8101) at $10 \mathrm{kHz}$.

Tables 1 and 2 tabulate experimentally measured values, estimated values using the expression derived in this paper and expression derived earlier for leakage inductance and their corresponding errors when compared with the experimentally measured values.

\section{Conclusion}

In this paper an improved expression for leakage inductance has been derived, using energy method. To observe the $H$-field pattern, FEM analysis has been carried out on a secondary shorted transformer, with primary excited. Experimental results show that the formula derived in this paper has better accuracy. It is observed that the leakage inductance estimated using improved expression $L_{\text {leak }}$ has less deviation from $L_{\text {exp }}$ when compared with leakage inductance estimated

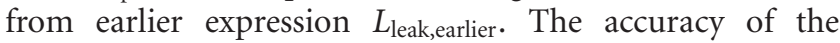
estimated value is improved due to consideration of flux that is extending into air.

\section{References}

[1] S. D. Johnson, A. F. Witulski, and R. W. Erickson, "Comparison of resonant topologies in high-voltage dc applications," IEEE Transactions on Aerospace and Electronic Systems, vol. 24, no. 3, pp. 263-274, 1988.

[2] A. K. S. Bhat, A. Biswas, and B. S. R. Iyengar, "Analysis and design of (LC)(LC)-type series-parallel resonant converter," IEEE Transactions on Aerospace and Electronic Systems, vol. 31, no. 3, pp. 1186-1193, 1995.

[3] B. Yang, F. C. Lee, A. J. Zhang, and G. Huang, "LLC resonant converter for front end DC/DC conversion," in Proceedings of the 17th Annual IEEE on Applied Power Electronics Conference and Exposition Conference (APEC '02), vol. 2, pp. 1108-1112, Institute of Electrical and Electronics Engineers, 2002.

[4] J. A. Sabate, V. Vlatkovic, R. B. Ridley, F. C. Lee, and B. H. Cho, "Design considerations for high-voltage high-power fullbridge zero-voltage-switched pwm converter," in Proceedings of the 5th Annual Applied Power Electronics Conference and Exposition (APEC'90), pp. 275-284, Institute of Electrical and Electronics Engineers, 1990.

[5] J. F. Lazar and R. Martinelli, "Steady-state analysis of the LLC series resonant converter," in Proceedings of the 16th Annual Applied Power Electronics Conference and Exposition (APEC '01), vol. 2, pp. 728-735, Institute of Electrical and Electronics Engineers, 2001. 
[6] P. C. Todd, "Snubber circuits: theory, design and application," in Unitrode-Power Supply Design Seminar, 1993.

[7] William McMurray, "Selection of snubbers and clamps to optimize the design of transistor switching converters," IEEE Transactions on Industry Applications, vol. IA-16, no. 4, pp. 513-523, 1980.

[8] N. Mohan, T. M. Undeland, and W. P. Robbins, Power Electronics: Converters, Applications, and Design, vol. 1, John Wiley \& Sons, New York, NY, USA, 2003.

[9] R. Doebbelin, M. Benecke, and A. Lindemann, "Calculation of leakage inductance of core-type transformers for power electronic circuits," in Proceedings of the 13th Power Electronics and Motion Control Conference (EPE-PEMC '08), pp. 1280-1286, September 2008.

[10] A. A. Dauhajre, Modelling and estimation of leakage phenomena in magnetic circuits, Ph.D. thesis, California Institute of Technology, Pasadena, Calif, USA, 1986.

[11] W. T. McLyman and C. W. T. McLyman, Transformer and Inductor Design Handbook, Marcel Dekker, New York, NY, USA, 2004.

[12] Z. Ouyang, O. C. Thomsen, and M. Andersen, "The analysis and comparison of leakage inductance in different winding arrangements for planar transformer," in Proceedings of the International Conference on Power Electronics and Drive Systems (PEDS '09), pp. 1143-1148, November 2009.

[13] R. Doebbelin, R. Herms, C. Teichert, W. Schaetzing, and A. Lindemann, "Analysis methods and design of transformers with low leakage inductance for pulsed power applications," in Proceedings of the European Conference on Power Electronics and Applications, pp. 1-7, September 2007.

[14] W. G. Hurley and D. J. Wilcox, "Calculation of leakage inductance in transformer windings," IEEE Transactions on Power Electronics, vol. 9, no. 1, pp. 121-126, 1994. 

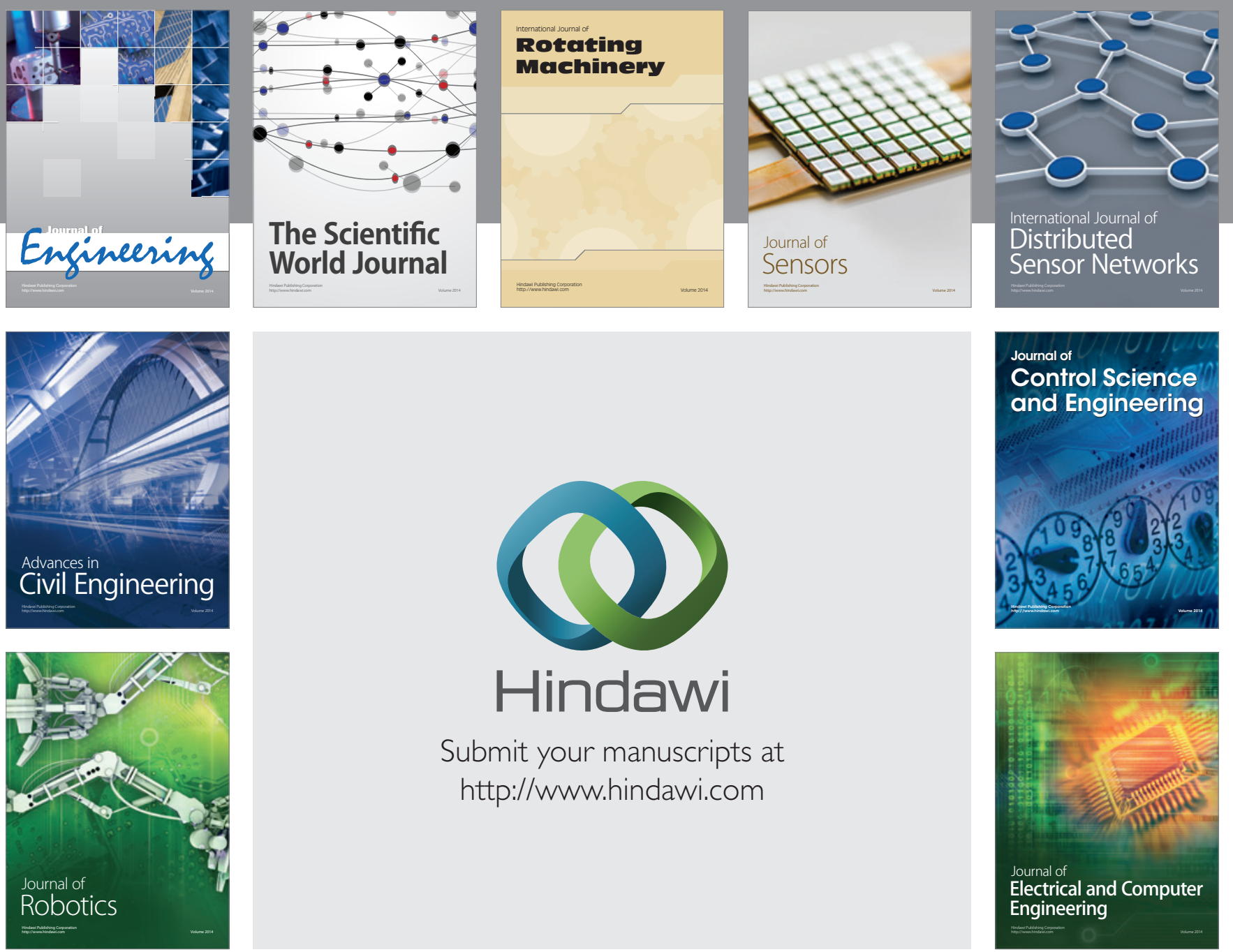

Submit your manuscripts at

http://www.hindawi.com
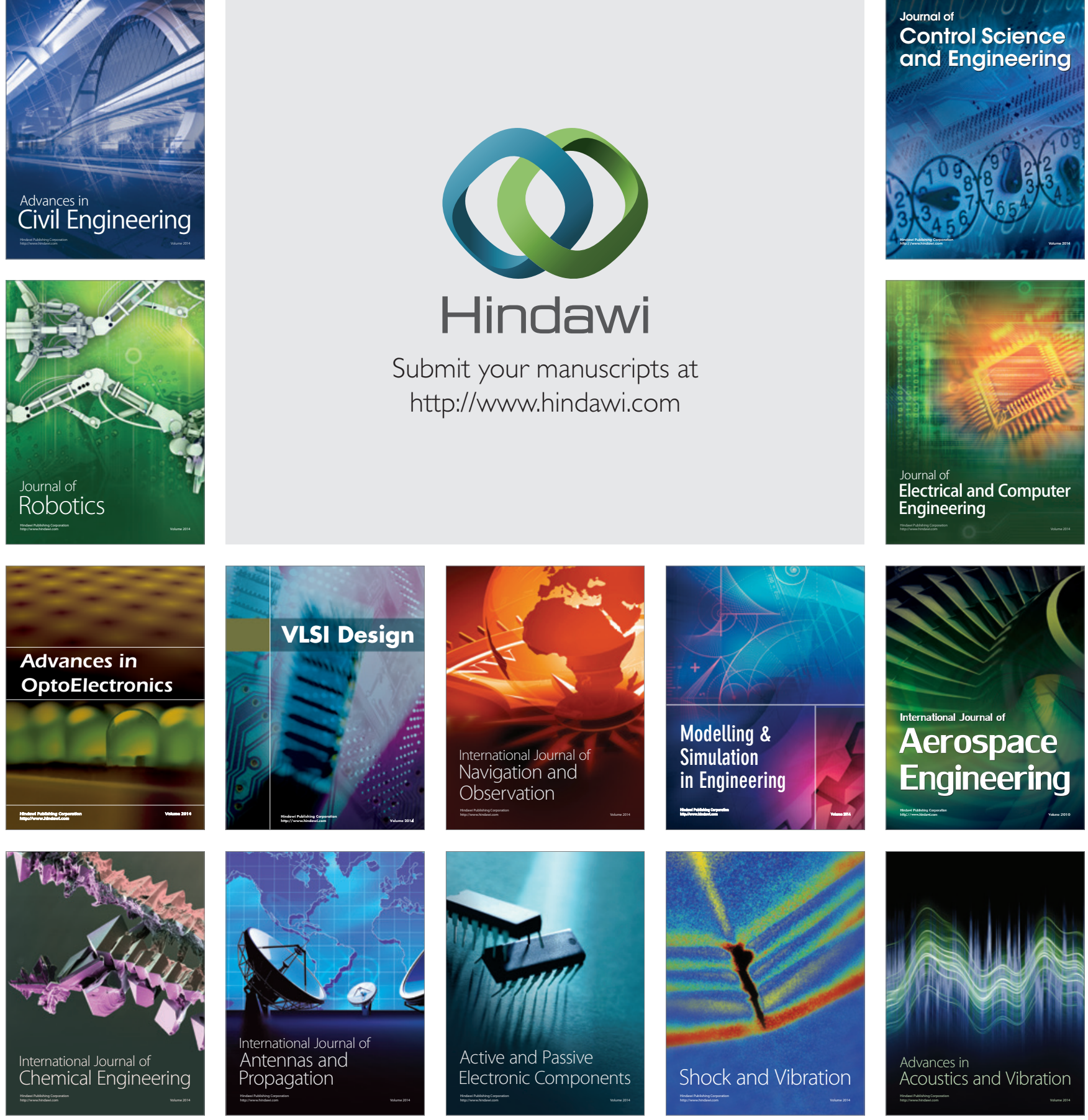